\title{
Evaluation of Elite Native Strawberry Germplasm for Resistance to Anthracnose Crown Rot Disease Caused by Colletotrichum Species
}

\author{
K.S. Lewers ${ }^{1}$, W.W. Turechek ${ }^{2}$, S.C. Hokanson ${ }^{3}$, and J.L. Maas \\ U.S. Department of Agriculture, Agricultural Research Service, Beltsville Agricultural Research \\ Center, Fruit Laboratory, Bldg. 010A, BARC-West, 10300 Baltimore Ave., Beltsville, MD 20705-2350 \\ J.F. Hancock and S. Serçe ${ }^{4}$ \\ Department of Horticulture, Michigan State University, East Lansing, MI 48824 \\ B.J. Smith \\ U.S. Department of Agriculture, Agricultural Research Service, Thad Cochran Southern Horticultural \\ Laboratory, Small Fruit Research Unit, P.O. Box 287, 810 Highway 26 W, Poplarville, MS 39470
}

ADDITIONAL INDEX woRDs. Fragaria ×ananassa, Fragaria virginiana, Fragaria chiloensis, Colletotrichum acutatum, Colletotrichum fragariae, Colletotrichum gloeosporioides

\begin{abstract}
Anthracnose crown rot of cultivated strawberry (Fragaria $\times$ ananassa Duchesne ex Rozier) has been a major disease problem in the strawberry producing regions of the southeastern United States since the early $1970 \mathrm{~s}$. Chemical controls are often inadequate, but use of resistant cultivars is seen as a credible option for managing this disease. Only a small portion of Fragaria $\mathbf{L}$. germplasm has been screened for resistance to anthracnose crown rot. A core subset of the Fragaria collection maintained at the U.S. Department of Agriculture National Clonal Repository in Corvallis, $O R$, has been constructed to contain an elite group of native $F$. virginiana Mill. and $F$. chiloensis (L.) Mill. This collection, referred to as the "core collection," has been characterized for many horticultural traits, including reactions to several common foliar diseases, resistance to black root rot (causal organisms unknown), and resistance to northern root-knot nematode (Meloidogyne hapla Chitwood) and root-lesion nematode [Pratylenchus penetrans (Cobb) Filipjev \& Shuurmans Stekhoven]. Our objective was to evaluate the core collection for resistance to a selection of isolates of three Colletotrichum Corda species known to cause strawberry anthracnose, Colletotrichum fragariae A.N. Brooks, Colletotrichum gloeosporioides (Penz.) Penz. \& Sacc. in Penz. [teleomorph Glomerella cingulata (Stoneman) Spauld. \& H. Schrenk], and Colletotrichum acutatum J.H. Simmonds (teleomorph Glomerella acutata J.C. Guerber \& J.C. Correll). No Fragaria subspecies or geomorph was more resistant than any other; rather, individual genotypes within these groups were identified as sources from which resistance can be obtained. Collecting germplasm in areas of intense disease pressure may not be as beneficial as one might assume, at least where anthracnose crown rot disease is concerned.
\end{abstract}

Anthracnose crown rot and fruit rot caused by species of the fungal genus Colletotrichum produce significant losses in strawberry (Fragaria ×ananassa) production with crown rot, resulting in plant death and fruit rot, which in turn results in some percentage of unmarketable fruit (Maas, 1998). Anthracnose crown rot has been a major disease problem in the strawberry producing regions of the southeastern United States since the 1970s. Although initially considered a southeastern United States problem, anthracnose disease has increasingly

Received for publication 22 Mar. 2007. Accepted for publication 20 Sept. 2007. This study was funded in part by a USDA-ARS Germplasm Evaluation Grant. Mention of trade names or commercial products in this publication is solely for the purpose of providing specific information and does not imply recommendation or endorsement by the U.S. Department of Agriculture or Michigan State University.

The authors thank Drs. Jim Ballington, Craig Chandler, Mike Ellis, Freddi Hammerschlag, and the anonymous reviewers for their helpful comments.

${ }^{1}$ Corresponding author. E-mail: kim.lewers@ars.usda.gov.

${ }^{2}$ Current address: USDA-ARS U.S. Horticultural Research Laboratory, 2001 South Rock Road, Fort Pierce, FL 34945.

${ }^{3}$ Current address: Department of Horticulture Science, University of Minnesota, St. Paul, MN 55108.

${ }^{4}$ Current address: Mustafa Kemal University, Faculty of Agriculture, Department of Horticulture, Antakya, Hatay, 31034 Turkey. become a significant problem in other strawberry production regions in the United States and the world (Freeman et al., 1998; Howard et al., 1992; Maas, 1998).

Anthracnose is incited by the fungal species Colletotrichum fragariae, Colletotrichum gloeosporioides (teleomorph Glomerella cingulata) (Smith and Black, 1990), and Colletotrichum acutatum (teleomorph Glomerella acutata). Colletotrichum fragariae causes crown and fruit rot but is rarely found outside the southeastern United States, and its host range is limited (Smith, 1998a, 1998b). Colletotrichum gloeosporioides most commonly causes crown rot but can also cause fruit rot. Colletotrichum acutatum causes a destructive fruit rot (Howard et al., 1992; Smith, 1998a) in addition to runner and petiole lesions, and it can also cause crown rot (Smith, 1998b). Both C. gloeosporioides and C. acutatum have broad host ranges, including apple (Malus $\times$ domestica Borkh.), key lime [Citrus aurantiifolia (Christm.) Swingle], mango (Mangifera indica L.), peach [Prunus persica (L.) Batsch], sweet orange [Citrus sinensis (L.) Osbeck], blueberry (Vaccinium corymbosum L.), and almond [Prunus dulcis (Mill.) D. A. Webb] (Farr et al., 1989; Freeman et al., 1998; Peres et al., 2005; Smith, 1998a, 1998b).

For control of various plant diseases, integrated pest management and sustainable agriculture strategies often 
incorporate the use of resistant or tolerant cultivars. However, very few cultivars resistant to anthracnose crown rot currently are available in North America. Only 'Pelican' is resistant to both anthracnose fruit and crown rot (Shuman, 2001; Smith et al., 1998). Though four parent clones (Galletta et al., 1993) are resistant to anthracnose crown rot, 'Gem Star' (Chang, 2002a) and 'Treasure' (Chang, 2002b) are the only cultivars other than 'Pelican' reported to be resistant to anthracnose crown rot.

Selection for additional cultivated strawberry genotypes resistant to anthracnose crown rot is a credible option for managing this disease (Ballington et al., 2002; Denoyes-Rothan and Guérin, 1996; Gupton and Smith, 1991; Hancock et al., 1991, 1996; Simpson et al., 1994; Smith et al., 1996). However, apparent "field resistance" (Olcott-Reid and Moore, 1995) may be due to genotype by environment interactions unfavorable to infection or spread, rather than to true genetic disease resistance (Smith and Black, 1987). Expression of resistance is strongly affected by interactions among environment, genotype, and isolate (Ballington and Milholland, 1993; Olcott-Reid and Moore, 1995; Smith and Black, 1987, 1990). In addition, individual isolates within and among the three Colletotrichum species vary in pathogenicity to Fragaria genotypes (Smith and Black, 1990).

A reliable assay has been used for 20 years to identify resistant strawberry genotypes (Smith and Black, 1987; Smith et al., 1990). Multiple isolates of Colletotrichum spp. may be used in this assay to screen for resistance to pathogenic strains collected from various hosts and geographic locations. Anthracnose-resistant genotypes (including US 70, US 159, US 292, US 438, and 'Pelican') selected using this assay have been grown in replicated field trials at the Small Fruit Research Station, Poplarville, MS, for 10 to 20 years under heavy anthracnose pressure without dying from anthracnose crown rot. Plants of commercial cultivars, including Chandler, grown in the same trials often died from anthracnose crown rot by late spring. While $C$. fragariae was the most common causal agent of anthracnose crown rot in these field trials, C. acutatum and C. gloeosporioides also were isolated from crowns of plants dying in the field. In addition, all three species have been isolated from symptomatic fruit on plants grown in these trials (B.J. Smith, unpublished data).

Only a small portion of $F$. ×ananassa germplasm has been screened for resistance to anthracnose crown rot (Smith and Black, 1990). The germplasm base of the cultivated strawberry is very narrow (Dale and Sjulin, 1990; Hancock and Luby, 1995; Sjulin and Dale, 1987); thus, there is not a large reservoir of germplasm among cultivars from which to draw resistance genes for developing new resistant cultivars. Hancock et al. (1993) suggested that the genetic diversity of $F$. ×ananassa should be expanded by introgressing genes from elite clones of wild native octoploid Fragaria species. Very little attention has been given to evaluation of wild octoploid Fragaria germplasm as potential sources of resistance to anthracnose. Moreover, the germplasm that has been evaluated has been screened with only a small number of Colletotrichum isolates that ultimately originated either from the southeastern United States or California. Only recently have some Fragaria virginiana clones from the southeastern U.S. been reported to be potential sources of genes for resistance to both $C$. acutatum and C. fragariae (J.R. Ballington, personal communication).

A core subset of the Fragaria collection maintained at the U.S. Department of Agriculture National Clonal Repository,
Corvallis, OR, has been constructed to contain an elite group of native $F$. virginiana and Fragaria chiloensis. This core subset is being characterized for many horticultural traits useful to breeders (Hancock et al., 2001a, 2001b), including reactions to several common foliar diseases, resistance to black root rot (causal organisms unknown) (Hancock et al., 2001b, 2002), and resistance to northern root-knot nematode (Meloidogyne hapla) and root-lesion nematode (Pratylenchus penetrans) (Pinkerton and Finn, 2005). Our objective in the present work was to evaluate many of the clones represented in the core collection for resistance to a selection of isolates of the three Colletotrichum species that can cause anthracnose crown rot.

\section{Materials and Methods}

Plant Material. Young runner plants of the $F$. ×ananassa cultivars Pelican (resistant) and Chandler (generally not resistant), eight clones of $F$. chiloensis, and 12 clones of $F$. virginiana from the core collection (Table 1) were rooted under intermittent mist. 'Pelican' and 'Chandler' served as negative and positive treatment controls, respectively. After about 2 weeks, the rooted plants were transplanted to $10 \times 10 \mathrm{~cm}^{2}$ plastic pots containing a 1:1 (by volume) mixture of Jiffy-Mix (JPA, West Chicago, IL) and pasteurized sand and grown for at least 6 weeks before inoculation in a greenhouse maintained at $28{ }^{\circ} \mathrm{C}$ day $/ 18^{\circ} \mathrm{C}$ night $\pm 6^{\circ} \mathrm{C}$ with a 16 -h photoperiod. Older leaves, runners, and flowers were removed $1-7 \mathrm{~d}$ before inoculation, and three or four young leaves remained on each plant at inoculation.

INOCULUM PRODUCTION AND INOCULATION. Isolates of C. acutatum (Goff and CA-1), C. fragariae (CF-63 and CF75), and C. gloeosporioides (CG-162) (Smith and Black, 1990) have been used for 20 years to identify resistant strawberry genotypes (Smith and Black, 1987; Smith et al., 1990) and were selected for this experiment. Isolates were initiated from silica gel cultures maintained at USDA/ARS in Poplarville, MS. Cultures were grown on potato dextrose agar (PDA) under continuous fluorescent light at room temperature $\left(20-28{ }^{\circ} \mathrm{C}\right)$. Conidial suspensions used for inoculations were prepared from 7- to 14-d-old cultures. Inoculum was prepared by flooding each PDA culture plate with sterile deionized water and gently scraping the agar surface with a glass rod to remove conidia. The resulting conidial suspension was filtered through cheesecloth, and the final conidial suspension was adjusted to $1.5 \times 10^{6}$ conidia/mL.

Inoculations were conducted separately for each isolate in three independent experiments. Before inoculation, plants within each genotype were sorted by vigor and placed in blocks so that each of the Colletotrichum isolates would be tested on plants having the same range of vigor. Within each block, plants of each genotype were assigned randomly to an inoculant treatment. A hand pump sprayer was used to apply the inoculum, or water as a control treatment, as a mist uniformly over the foliage of the plants to the point of runoff so that inoculum or water accumulated in the crowns at the petiole bases. All genotypes were inoculated with $C$. acutatum isolate Goff, most were inoculated with $C$. fragariae isolate CF-63, and genotypes with sufficient available plants were inoculated with the other three isolates. In 2000, all inoculations were done on 24 Jan. To account for genotype by environment effects, subsequent inoculations were done at different times of the year. In 2003, plants were inoculated on 16, 23, 25, and 29 
Table 1. Strawberry genotypes evaluated for reaction to infection by five isolates of three Colletotrichum species. ${ }^{2}$

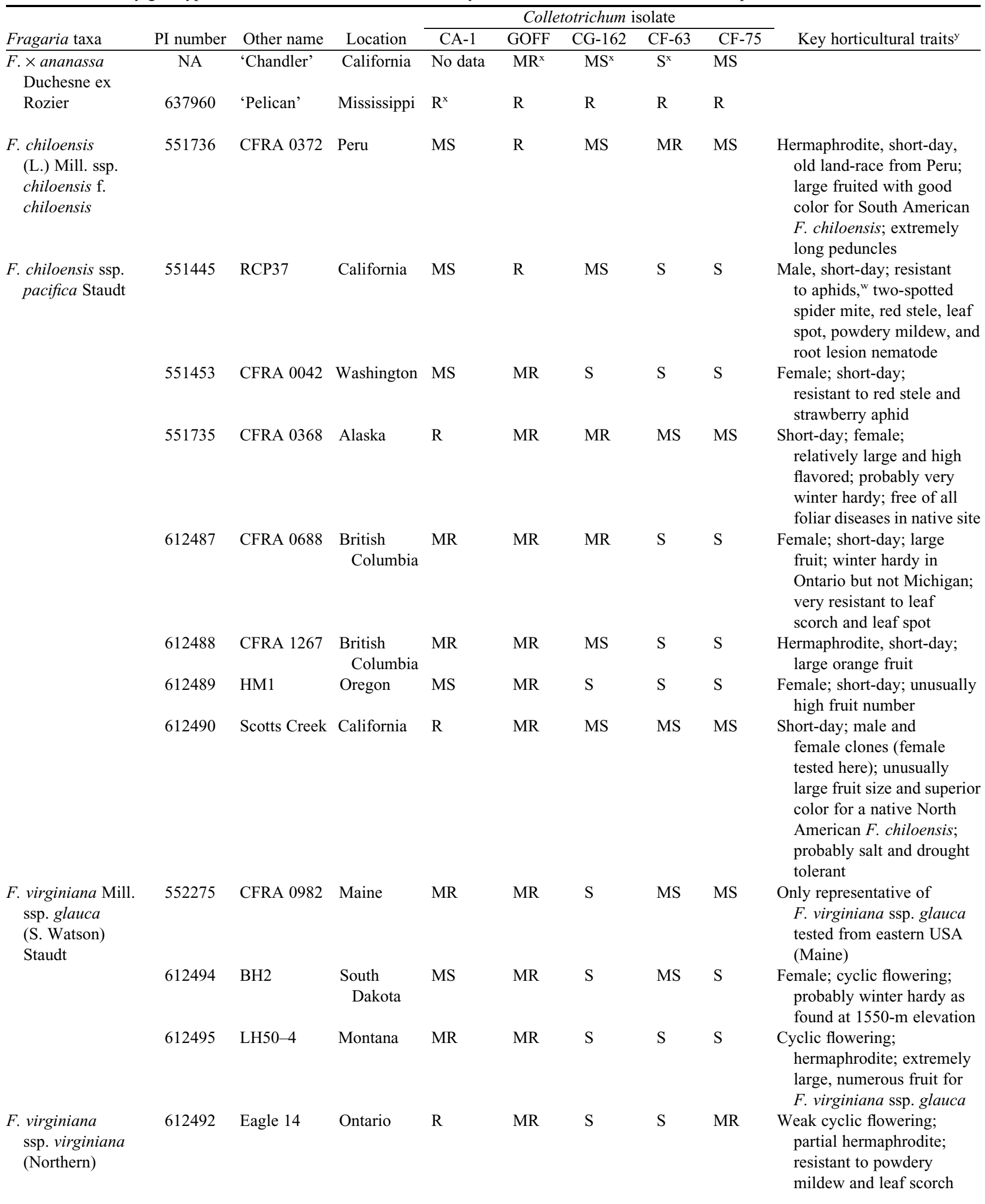

continued next page 
Table 1. Continued.

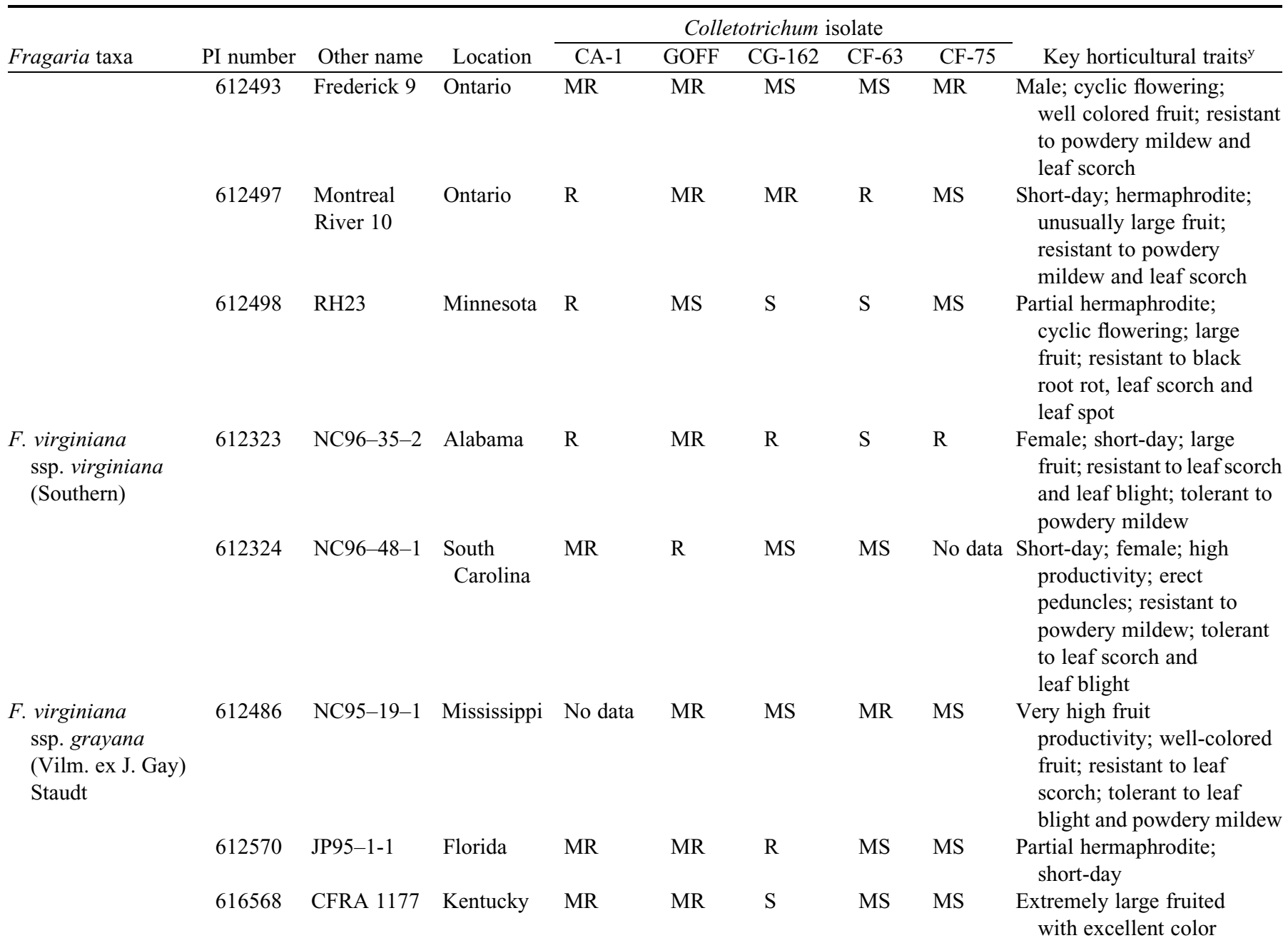

${ }^{\mathrm{z}}$ Genotypes are denoted by plant introduction (PI) number of the U.S. National Plant Germplasm System, cultivar name, accession or field collection name or number, and the state or country of original collection. Colletotrichum isolates were selected from three species: CA-1 and GOFF are isolates of C. acutatum; CG-162 is an isolate of C. gloeosporioides; and CF-63 and CF-75 are isolates of C. fragariae. Analyses of variance indicated significant differences between genotypes regarding response to the $C$. fragariae isolates and the $C$. gloeosporioides isolate but not with regard to response to either of the C. acutatum isolates.

${ }^{\mathrm{y}}$ Horticultural traits and taxonomic classification for wild strawberry genotypes are taken from Hancock et al. (2001a, 2001b, 2002).

${ }^{x}$ Disease severity was rated on a standardized scale of 0 to $6(0=$ healthy plant with no visible symptoms; $1=$ petiole lesions $<3 \mathrm{~mm}$ long; $2=$ petiole lesions 3-10 $\mathrm{mm}$ long; $3=$ petiole lesions $>10$ to $<20 \mathrm{~mm}$ long; $4=$ petiole lesions $>20 \mathrm{~mm}$ long; $5=$ youngest leaf wilted; $6=$ dead plant). Analyses of variance indicated significant genotype by year interaction effects. Therefore, a genotype with an average disease-severity rating $\leq 2$ in any of the years tested was considered resistant (R), a genotype with an average rating $\leq 3$ was considered moderately resistant (MR), a genotype with an average rating $\leq 4$ was considered moderately susceptible (MS), and a genotype with an average rating $>4$ for any year was considered susceptible $(\mathrm{S})$.

${ }^{w}$ Leaf scorch [Diplocarpon earlianum (Ellis \& Everh.) F.A. Wolf], leaf spot [Mycosphaerella fragariae (Tul.) Lindau], verticillium wilt (Verticillium C. G. D. Nees ex Wallroth.), two-spotted spider mite (Tetranychus urticae Koch.), red stele (Phytophthora fragariae Hickman), powdery mildew [Sphaerotheca macularis (Wallr.:Fr.) Jacz. f. sp. fragariae Peries], root lesion nematode [Pratylenchus penetrans (Cobb) Filipjev and Schuurmans Stekhoven], root-knot nematode (Meloidogyne hapla Chitwood), black root rot [causal organism(s) not known], leaf blight [Phomopsis obscurans (Ellis \& Everh.) Sutton], and strawberry aphid (Chaetosiphon Mordvilko).

Sept.; in 2005, plants were inoculated on 16, 21, 27 Mar., and 7 Apr.

Treated plants were immediately placed in a dew chamber at $100 \%$ relative humidity and $30{ }^{\circ} \mathrm{C}$ for $48 \mathrm{~h}$ and then into a greenhouse for 4 weeks with a temperature of $22 \pm 7^{\circ} \mathrm{C}$. To prevent cross-contamination, plants were randomized within inoculant group within block when placed in the dew chamber for incubation and subsequently in the greenhouse. Plants inoculated with the same isolate or the water control were placed on the same shelf in the dew chamber and grouped together in the greenhouse until they were rated.

Disease development based on petiole lesion length and crown rot symptoms was assessed $30 \mathrm{~d}$ after inoculation (Smith and Black, 1987). Disease severity was rated on a standardized scale of 0 to $6(0=$ healthy plant with no visible symptoms; $1=$ petiole lesions $<3 \mathrm{~mm}$ long; $2=$ petiole lesions $3-10 \mathrm{~mm}$ long; 
Table 2. Mixed-model analysis of the effects of Colletotrichum isolate and Fragaria subspecies (taxa) on the severity of anthracnose crown rot in greenhouse screenings of six subspecies of strawberry conducted in 2000, 2003, and 2005. ${ }^{\mathrm{z}}$

\begin{tabular}{lccc}
\hline Source of variation & $\begin{array}{c}\text { Numerator } \\
\text { df }\end{array}$ & $\begin{array}{c}\text { Test } \\
\text { statistic }^{\mathrm{y}}\end{array}$ & $P$ \\
\hline Fixed effects & & $F$ & $P>F$ \\
$\quad$ Isolate & 4 & 6.07 & 0.0129 \\
Taxa & 5 & 2.26 & 0.1361 \\
$\quad$ Isolate $\times$ taxa & 20 & 2.47 & 0.0092 \\
Random effects & & $\chi^{2}$ & $P>\chi^{2}$ \\
Year & 4 & 223.6 & $<0.0001$ \\
Block $($ year $)$ & 1 & 33.8 & $<0.0001$ \\
Year $\times$ isolate & 2 & 30.5 & $<0.0001$ \\
Year $\times$ taxa & 2 & 49.6 & $<0.0001$ \\
Year $\times$ isolate $\times$ taxa & 1 & 1.7 & 0.1923
\end{tabular}

Residual

$(1111.9)^{\mathrm{x}}$

${ }^{\mathrm{z}}$ Data were combined over years and analyzed as a multiyear split-plot design treating year as a random effect. Sources of variation are sorted according to whether they were considered fixed effects or random effects.

${ }^{\mathrm{y}} F$ tests were performed on fixed effects with numerator df values shown in the table and denominator df values of $8.65,9.0$, and 35.2 for the effects of isolate, taxa, and its interaction, respectively; the denominator df values were calculated using the KENWARDROGER method (Kenward and Roger, 1997). Likelihood ratio $\chi^{2}$ tests were performed on random effects with df values shown in table. Column shows the difference between the $-2 \cdot \log$ likelihoods of the full and reduced models.

${ }^{\mathrm{x}}$ The $-2 \cdot \log$ likelihood of the full model is shown in parentheses.

$3=$ petiole lesions $>10$ but $<20 \mathrm{~mm}$ long; $4=$ petiole lesions $>20 \mathrm{~mm}$ long; $5=$ youngest leaf wilted; $6=$ dead plant), as described previously (Smith and Black, 1987). According to this rating, a genotype with an average disease-severity rating of $\leq 2$ is considered resistant, a genotype with an average rating of $>2$ to 3 is considered moderately resistant, a genotype with an average rating of $>3$ to $<4$ is considered moderately susceptible, and a genotype with a rating of $\geq 4$ is considered susceptible.

EXPERIMENTAL DESIGN AND STATISTICAL ANALYSES. The entire experiment was conducted three times, once in each of 3 years. The individual experiments were unbalanced within years because not all genotypes were included in all blocks. The experiments also were unbalanced across years because the number of blocks was unequal across experiments, and not all genotypes were inoculated with all of the isolates in each year because of limited plant material. Data were combined over years and analyzed as a multiyear split-plot design treating year as a random effect, inoculum source (i.e., Colletotrichum isolate) served as the whole-plot factor and either strawberry genotype or Fragaria subspecies (taxa) served as the split-plot factor. The split-plot factor was arranged in a randomized complete block design with four to eight replications (blocks) per experiment, depending upon the variability in plant vigor, with plants of similar vigor together in a block.

For all analyses, data were first transformed by adding 0.5 to the disease-severity rating and then calculating the square root. The data were analyzed as a generalized linear mixed model (GLMM) using the SAS routine PROC MIXED (version 9.1; SAS Institute, Cary, NC) with the default restricted maximum likelihood (REML) method for parameter estimation. Strawberry genotype or Fragaria taxonomic group (taxa) and pathogen isolate were considered fixed effects; year, blocks, and interactions of year with fixed effects were considered random effects. $F$ tests were used to determine if differences between means within the fixed effects (genotype, taxa, isolate) were significant. However, the variance component estimates for each of the random effects were tested (i.e., $H_{0}: \chi^{2}=0$ ) using likelihood ratio $\chi^{2}$ tests rather than relying on the Wald $z$ test provided as part of the default output of PROC MIXED due to inadequate $\mathrm{df}$ for the test (Littell et al., 1996). To perform the likelihood ratio $\chi^{2}$ tests, the difference between -2 times the $\log$ likelihood of the full model and the corresponding $\log$

Table 3. Mixed-model analysis of the effects of Colletotrichum isolate and strawberry genotype on the severity of anthracnose crown rot in greenhouse screenings of 22 genotypes of strawberry conducted in 2000, 2003, and 2005. ${ }^{\mathrm{z}}$

\begin{tabular}{lccc}
\hline Source of variation & $\begin{array}{c}\text { Numerator } \\
\text { df }\end{array}$ & $\begin{array}{c}\text { Test } \\
\text { statistic }^{\mathrm{y}}\end{array}$ & $P$ \\
\hline Fixed effects & 4 & $F$ & $P>F$ \\
$\quad$ Isolate & 21 & 6.28 & 0.0155 \\
$\quad$ Genotype & 81 & 1.58 & 0.1180 \\
$\quad$ Isolate $\times$ genotype & & 1.78 & 0.0024 \\
Random effects & 4 & 293.3 & $P>\chi^{2}$ \\
$\quad$ Year & 1 & 50.4 & $<0.0001$ \\
$\quad$ Block $($ year $)$ & 2 & 68.1 & $<0.0001$ \\
$\quad$ Year $\times$ isolate & 2 & 122.3 & $<0.0001$ \\
$\quad$ Year $\times$ genotype & 1 & 15.0 & 0.0001 \\
$\quad$ Year $\times$ isolate $\times$ genotype & & $(943.2)^{\mathrm{x}}$ & \\
Residual & &
\end{tabular}

$\overline{{ }^{\mathrm{z}} \text { Data were combined over years and analyzed as a multiyear split-plot }}$ design treating year as a random effect. Sources of variation are grouped according to whether they were considered fixed effects or random effects in the analysis of variance.

${ }^{\mathrm{y}} F$ tests were performed on fixed effects with numerator df values shown in table and denominator df values of 7.56, 32.9, and 112 for the effects of isolate, genotype, and its interaction, respectively; the denominator df values were calculated using the KENWARDROGER method (Kenward and Roger, 1997). Likelihood ratio $\chi^{2}$ tests were performed on random effects with df values shown in table. Column shows the difference between the $-2 \cdot \log$ likelihoods of the full and reduced models.

${ }^{\mathrm{x}}$ The $-2 \cdot \log$ likelihood of the full model is shown in parentheses.

Table 4. $F$ tests of the interaction of Fragaria taxonomic grouping (taxa) or genotype with Colletotrichum isolate to determine if differences between taxa or differences between individual genotypes were observed.

\begin{tabular}{lccccccc}
\hline & \multicolumn{3}{c}{ Taxa } & & \multicolumn{3}{c}{ Genotype } \\
\cline { 2 - 4 } \cline { 6 - 8 } Isolate & df & $F$ & $P>F$ & & df & $F$ & $P>F$ \\
\hline GOFF & 19.2 & 0.65 & 0.6653 & & 79.3 & 0.43 & 0.9833 \\
CA-1 & 27.5 & 0.31 & 0.9009 & & 98.1 & 0.70 & 0.8151 \\
CG-162 & 22.1 & 0.90 & 0.4955 & & 93.5 & 1.88 & 0.0215 \\
CF-63 & 19.1 & 4.86 & 0.0049 & & 79.7 & 2.90 & 0.0003 \\
CF-75 & 27.9 & 3.91 & 0.0082 & & 110 & 2.39 & 0.0022
\end{tabular}

${ }^{\mathrm{z}} F$ tests were performed with numerator df value of 5 for comparisons of isolates within taxa and values of $21,19,21,21$, and 20 for GOFF, CA-1, CG-162, CF-63, and CF-75, respectively, for comparisons within genotype; the denominator df values were calculated using the KENWARDROGER method (Kenward and Roger, 1997). 
likelihood calculated from the reduced model (the model with the random effect and its interactions removed from the full model) was calculated for each of the random effects in the full model. This difference has a $\chi^{2}$ distribution with $\mathrm{df}$ equal to the difference in the number of covariance parameters between the full and reduced models.

The interaction terms, isolate by genotype and isolate by taxa, were significant in their respective analyses. Therefore, mean comparisons of strawberry genotypes or taxa were performed within isolate groups. This was accomplished using the SLICE option of PROC MIXED (Littell et al., 1996). To determine if different genotypes or taxa responded differently to the same isolate, pairwise differences were calculated from the LSMEANS and the PDIFF options of PROC MIXED and letter designations were assigned to significant groupings using the macro, \%MULT (Piepho, 2005). Both the actual means and the estimated means were back-transformed by calculating the square and then subtracting 0.5 for presentation so they would correspond to the rating system used.

\section{Results and Discussion}

Eight core collection clones of $F$. chiloensis and 12 of $F$. virginiana from widely separated geographic origins were evaluated with two cultivars of $F$. Xananassa-one generally resistant and the other partially susceptible-for resistance to anthracnose crown rot (Table 1). This was done by inoculation with two isolates of $C$. acutatum (Goff and CA-1), two of C. fragariae (CF-63 and CF-75), and one of C. gloeosporioides (CG-162) (Smith and Black, 1990). Although the selected isolates may not represent all the genetic variability present within these three Colletotrichum species, they have been used successfully for 20 years to identify resistant strawberry genotypes (Smith and Black, 1987; Smith et al., 1990).

When averaged across all isolates, disease-severity ratings were not significantly different among strawberry genotypes or taxa (Tables 2 and 3) (i.e., the main
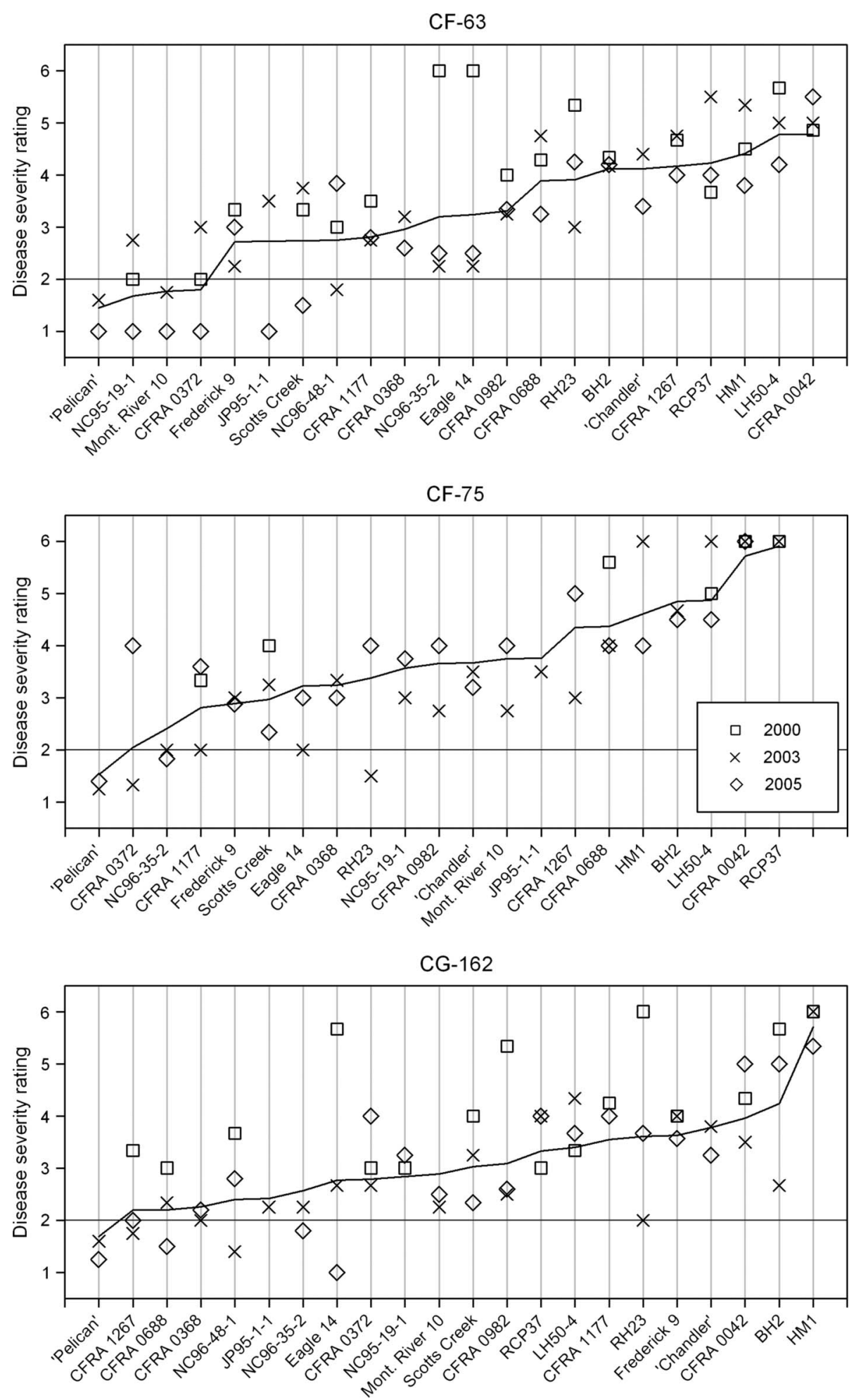

Fig. 1. Mean anthracnose crown rot severity scores for 22 genotypes of strawberry inoculated with one of five isolates of Colletotrichum in greenhouse screenings conducted in 2000, 2003, and 2005. The Colletotrichum isolates are from three species: C. acutatum (Goff and CA-1), C. fragariae (CF-63 and CF-75), and C. gloeosporioides (CG-162). Disease severity was rated for individual plants of genotypes on a standardized scale of 0 to $6(0=$ healthy plant with no visible symptoms; $1=$ petiole lesions $<3 \mathrm{~mm}$ long; $2=$ petiole lesions $3-10$ $\mathrm{mm}$ long; $3=$ petiole lesions $>10$ to $<20 \mathrm{~mm}$ long; $4=$ petiole lesions $>20 \mathrm{~mm}$ long; $5=$ youngest leaf wilted; $6=$ dead plant). Individual disease-severity ratings were averaged for each genotype within year. The solid line represents the least-square means for each genotype combined across years. A genotype with an average diseaseseverity rating $\leq 2$ in any of the years tested was considered resistant, a genotype with an average rating $\leq 3$ was considered moderately resistant, a genotype with an average rating $\leq 4$ was considered moderately susceptible, and a genotype with an average rating $>4$ for any year was considered susceptible. 
effects of genotypes and taxa were not significant). However, significant differences among strawberry genotypes or taxa could be detected within isolate groupings (Table 4; Fig. 1). When plants were inoculated with either C. acutatum isolate, no significant differences in disease-severity ratings were detected among strawberry genotypes or taxa. However, there were significant differences in disease-severity ratings among either strawberry genotypes or taxa when plants were inoculated with either of the two C. fragariae isolates (Table 4; Fig. 1). There also were significant effects among genotypes but not among strawberry taxa when plants were inoculated with C. gloeosporioides (Fig. 1; Table 4). The random effect of year and its interaction with strawberry genotypes or taxa was significant in both analyses. A significant year effect is not unusual given the differences that could be expected in planting material and environment from one year to the next (Gomez and Gomez, 1984).

No individual strawberry taxonomic group (taxa) stood out as being more likely to contain resistant genotypes across pathogen isolates. The analysis showed no significant differences between taxa when inoculated with $C$. acutatum or C. gloeosporioides isolates. Only when inoculated with the two $C$. fragariae isolates were significant differences among taxa detected (Table 4). The mean level of crown rot for each taxon when inoculated with these two isolates is presented in Table 5. Although F. chiloensis f. chiloensis ssp. chiloensis had the lowest level of crown rot when inoculated with the two isolates, this taxon was represented by only one genotype (PI 551736, CFRA 0372), and the level of infection was not significantly different from those of at least two other taxa. In addition, the level of crown rot on the geographically separated (northern and southern) clones (geomorphs) of $F$. virginiana ssp. virginiana was not statistically different (Table 5).

The susceptible control cultivar Chandler was not resistant to any of the isolates used, though it was rated moderately

Table 5. Least-square means of the crown rot severity ratings for Fragaria taxa inoculated with Colletotrichum fragariae isolate CF-63 or CF-75. ${ }^{\mathrm{z}}$

\begin{tabular}{lll}
\hline & \multicolumn{2}{c}{ C. fragariae isolate } \\
\cline { 2 - 3 } Fragaria taxa & \multicolumn{1}{c}{ CF-63 } & CF-75 \\
\hline F. virginiana ssp. glauca & $4.05^{\mathrm{y}} \mathrm{a}^{\mathrm{x}}$ & $4.40 \mathrm{a}$ \\
F. chiloensis ssp. pacifica & $3.81 \mathrm{ab}$ & $4.36 \mathrm{a}$ \\
F. virginiana ssp. virginiana (northern) & $2.99 \mathrm{abc}$ & $3.29 \mathrm{ab}$ \\
F. $\times$ ananassa & $2.64 \mathrm{bd}$ & $2.54 \mathrm{~b}$ \\
F. virginiana ssp. virginiana (southern) & $2.56 \mathrm{~cd}$ & $2.95 \mathrm{~b}$ \\
F. chiloensis f. chiloensis ssp. chiloensis & $1.78 \mathrm{~d}$ & $1.99 \mathrm{~b}$ \\
\hline
\end{tabular}

${ }^{\mathrm{Z}}$ Individual disease-severity ratings were averaged for each genotype, and the means presented are the back-transformed least-square means for each strawberry species.

${ }^{y}$ Disease severity was rated for individual plants of genotypes on a standardized scale of 0 to $6(0=$ healthy plant with no visible symptoms; $1=$ petiole lesions $<3 \mathrm{~mm}$ long; $2=$ petiole lesions $3-10 \mathrm{~mm}$ long; $3=$ petiole lesions $>10$ to $<20 \mathrm{~mm}$ long; $4=$ petiole lesions $>20 \mathrm{~mm}$ long; $5=$ youngest leaf wilted; $6=$ dead plant. A genotype with an average disease-severity rating $\leq 2$ in any of the years tested was considered resistant, a genotype with an average rating $\leq 3$ was considered moderately resistant, a genotype with an average rating $\leq 4$ was considered moderately susceptible, and a genotype with an average rating $>4$ for any year was considered susceptible.

${ }^{x}$ Means followed by the same letter are not significantly different from each other according to the PDIFF option of SAS PROC MIXED $(P<0.05)$. resistant to $C$. acutatum isolate Goff. In fact, most genotypes were rated resistant or moderately resistant to the $C$. acutatum isolates, but there were no significant differences among genotypes when inoculated with either $C$. acutatum isolate (Table 4). This is not terribly surprising because C. acutatum is noted more for causing fruit rot than crown rot (Maas, 1998). The water-inoculated control plants all received a rating of resistant (data not shown).

The significant genotype by year interactions that were observed when the genotypes were inoculated with the two C. fragariae isolates and the C. gloeosporioides isolate (Fig. 1; Table 4) suggested that a genotype should be considered resistant to an isolate only if the mean disease-severity rating indicated it was resistant $(\leq 2)$ each year tested. Likewise, a genotype should be considered moderately resistant to an isolate only if the mean disease-severity rating indicated it was either resistant $(\leq 2)$ or moderately resistant ( $>2$ to 3 ) each year tested. 'Pelican' and Montreal River 10 were rated resistant to CF-63, while NC95-19-1 and CFRA 0372 were rated moderately resistant to CF-63 (Fig. 1). 'Pelican' and NC96-35-2 were rated resistant to $\mathrm{CF}-75$, while Frederick 9 and Eagle 14 were rated moderately resistant to CF-75. 'Pelican' was rated resistant to CG-162 while CFRA 0688, CFRA 0368, JP95-1-1, NC96-35-2, and Montreal River 10 were rated moderately resistant, but JP95-1-1 was tested only 1 year. The variability of responses to this isolate was greater than to the two C. fragariae isolates. Although 'Pelican' was the only genotype that was rated resistant to all of the isolates, the other genotypes that were rated resistant or moderately resistant should still provide the basis for development of resistant cultivars. Resistance to multiple isolates is desirable to help enlarge the geographic area in which a new cultivar may be grown, but resistance to all available isolates of all Colletotrichum species may not be necessary for every cultivar development program. It would be desirable for new cultivars to be resistant to multiple $C$. acutatum and C. gloeosporioides isolates, as these species have wide host ranges and are distributed throughout the world, but C. fragariae is rarely found outside the southeastern United States, and its host range is limited to strawberry and a few weed hosts, so cultivars developed for regions outside the southeastern United States may not need to be resistant to any C. fragariae isolates.

New searches for additional genotypes resistant to different Colletotrichum isolates should not be limited to any particular Fragaria subspecies or geomorph. Individual genotypes from any of the subspecies or geomorphs can be potential sources of parental material for development of resistant cultivars. This is indicated by the significant interaction effects for Colletotrichum isolates and either strawberry genotypes or taxa (Table 4). It is more important to identify genotypes that will be most advantageous in a regional cultivar development program and then to evaluate them in order to identify those which also are resistant.

\section{Literature Cited}

Ballington, J.R. and R.D. Milholland. 1993. Screening strawberries for resistance to Colletotrichum acutatum in North Carolina. Acta Hort. 348:442-448.

Ballington, J.R., J.L. Shuman, B.J. Smith, S.C. Hokanson, and G. Giménez. 2002. Breeding strawberries (Fragaria ×ananassa) 
for resistance to anthracnose caused by Colletotrichum acutatum. Acta Hort. 567:89-92.

Chang, P. P.-C. 2002a. Strawberry plant called 'Gem Star'. United States Patent PP12,377. U.S. Patent and Trademark Office, Washington, DC.

Chang, P. P.-C. 2002b. Strawberry plant called 'Treasure'. United States Patent PP12,414. U.S. Patent and Trademark Office, Washington, DC.

Dale, A. and T.M. Sjulin. 1990. Few cytoplasms contribute to North American strawberry cultivars. HortScience 25:1341-1342.

Denoyes-Rothan, B. and G. Guérin. 1996. Comparison of six inoculation techniques with Colletotrichum acutatum on cold stored strawberry plants and screening for resistance to this fungus in French strawberry collections. Eur. J. Plant Pathol. 102:615-621.

Farr, D.F., G.F. Bills, G.P. Chamuris, and A.Y. Rossman. 1989. Fungi on plants and plant products in the United States. APS Press, St. Paul, MN.

Freeman, S., T. Katan, and E. Shabi. 1998. Characterization of Colletotrichum species responsible for anthracnose diseases of various fruits. Plant Dis. 82:596-605.

Galletta, G.L., B.J. Smith, and C.L. Gupton. 1993. Strawberry parent clones US 70, US 159, US 292, and US 438 resistant to anthracnose crown rot. HortScience 28:1055-1056.

Gomez, K.A. and A.A. Gomez. 1984. Statistical procedures for agricultural research. Wiley-Interscience, New York.

Gupton, C.L. and B.J. Smith. 1991. Inheritance of resistance to Colletotrichum species in strawberry. J. Amer. Soc. Hort. Sci. 116:724-727.

Hancock, J.F., P.W. Callow, A. Dale, J.J. Luby, C.E. Finn, S.C. Hokanson, and K.E. Hummer. 2001a. From the Andes to the Rockies: native strawberry collection and utilization. HortScience 36:221-225.

Hancock, J.F., A. Dale, and J. Luby. 1993. Should we reconstitute the strawberry? Acta Hort. 348:86-93.

Hancock, J.F., C.A. Finn, S.C. Hokanson, J.J. Luby, B.L. Goulart, K. Demchak, P.W. Callow, S. Serçe, A.M.C. Schilder, and K.E. Hummer. 2001b. A multistate comparison of native octoploid strawberries from North and South America. J. Amer. Soc. Hort. Sci. 126:579-586.

Hancock, J.F., S.C. Hokanson, C.E. Finn, and K.E. Hummer. 2002. Introducing a supercore collection of wild octoploid strawberries. Acta Hort. 567:77-79.

Hancock, J.F. and J.J. Luby. 1995. Adaptive zones and ancestry of the most important North American strawberry cultivars. Fruit Var. J. 49:85-89.

Hancock, J.F., J.L. Maas, C.H. Shanks, P.J. Breen, and J.J. Luby. 1991. Strawberries (Fragaria spp.). Acta Hort. 290:491-546.

Hancock, J.F., D.H. Scott, and F.J. Lawrence. 1996. Strawberries, p. 419-470. In: J. Janick and J.N. Moore (eds.). Fruit breeding, Vol. II: Vine and small fruit crops. Wiley, New York.
Howard, C.M., J.L. Maas, C.K. Chandler, and E.E. Albregts. 1992. Anthracnose of strawberry caused by the Colletotrichum complex in Florida. Plant Dis. 76:976-981.

Kenward, M.G. and J.H. Roger. 1997. Small sample inference for fixed effects from restricted maximum likelihood. Biometrics 53:983-997.

Littell, R.C., G.A. Milliken, W.W. Stroup, and R.D. Wolfinger. 1996. SAS system for mixed models. SAS Institute Inc., Cary, NC.

Maas, J.L. 1998. Compendium of strawberry diseases. 2nd ed. APS Press, St. Paul, Minn.

Olcott-Reid, B. and J.N. Moore. 1995. Field reaction of strawberry cultivars and selections to anthracnose fruit rot, leather rot and gray mold in Arkansas. Fruit Var. J. 49:4-13.

Peres, N.A., L.W. Timmer, J.E. Adaskaveg, and J.C. Correll. 2005. Lifestyles of Colletotrichum acutatum. Plant Dis. 89:784-796.

Piepho, H.-P. 2005. \%MULT. 19 July 2007. <http://www.uni-hohen heim.de/bioinformatik/beratung/toolsmacros/macrotool.html>.

Pinkerton, J. and C.E. Finn. 2005. Responses of strawberry species and cultivars to the root-lesion and northern root-knot nematodes. HortScience 40:33-38.

Shuman, J.L. 2001. Anthracnose fruit rot resistance in strawberry. PhD Diss., Horticultural Sci. Dept., North Carolina State Univ., Raleigh.

Simpson, D.W., C.Q. Winterbottom, J.A. Bell, and M.L. Maltoni. 1994. Resistance to a single UK isolate of Colletotrichum acutatum in strawberry germplasm from Europe. Euphytica 77:161-164.

Sjulin, T.M. and A. Dale. 1987. Genetic diversity of North American strawberry cultivars. J. Amer. Soc. Hort. Sci. 112:375-385.

Smith, B.J. 1998a. Anthracnose fruit rot, p. 31-33. In: J.L. Maas (ed.). Compendium of strawberry diseases. 2nd ed. APS Press, St. Paul, Minn.

Smith, B.J. 1998b. Anthracnose crown rot, p. 46-48. In: J.L. Maas (ed.). Compendium of strawberry diseases. 2nd ed. APS Press, St. Paul, Minn.

Smith, B.J. and L.L. Black. 1987. Resistance of strawberry plants to Colletotrichum fragariae affected by environmental conditions. Plant Dis. 71:834-837.

Smith, B.J. and L.L. Black. 1990. Morphological, cultural and pathogenic variation among Colletotrichum species isolated from strawberry. Plant Dis. 74:69-76.

Smith, B.J., L.L. Black, and G.J. Galletta. 1990. Resistance to Colletotrichum fragariae affected by seedling age and inoculation method. Plant Dis. 74:1016-1021.

Smith, B.J., G.J. Galletta, and C.G. Gupton. 1996. USDA-ARS strawberry resistance breeding, disease biology and management progress, p. 253-258. In: M.P. Pritts, C.K. Chandler, and T.E. Crocker (eds.). Proc. IV North Amer. Strawberry Conf., Univ. Florida Press, Gainesville, FL.

Smith, B.J., C.L. Gupton, G.J. Galletta, J.L. Maas, J.M. Enns, J.R. Ballington, Jr., R.J. Constantin, T.J. DiVittorio, and D. Himelrick. 1998. 'Pelican' strawberry. HortScience 33:1082-1084. 